\title{
ANALYSIS OF COMPLIANCE OF EAR PROTECTOR USAGE ON THE PREVENTION OF NOISE INDUCE HEARING LOSS AT STERILIZATION INSTALLATION
}

\section{Rosydiah Rahmawati, Nyilo Purnami* D, Makhmudyah Indri Cahyani}

Department of Ear Nose Throat (ENT) - Head Neck Surgery, Faculty of Medicine, Universitas Airlangga - Dr. Soetomo General Academic Hospital, Indonesia

\begin{abstract}
Noise Induce Hearing Loss (NIHL) is a work disease that is often found in industrial workers. The use of ear protectors that are in accordance with the standard along with the continuity of optimal use can reduce the risk of hearing loss due to noise in the workplace. Adherence to use ear protectors greatly affect the possibility of a person experiencing a more severe hearing loss. The purpose of this study is to prove the existence of relationship of compliance with the use of ear protectors with hearing loss due to noise in the installation of sterilization and laundry. This study used cross sectional methods. Seventeen samples were taken by consecutive sampling for audiometry examination and measurement of compliance with the use of Ear Protective Equipment. Respondents received an average score of 1.86 indicating that compliance with the use of ear protectors was sufficient. Based on the results of the measurement of the auditory threshold in 17 respondents as many as 4 respondents (23\%) normal hearing and as many as 13 respondents (77\%) experienced NIHL. The results of statistical tests with Pearson correlation show that the Pearson correlation coefficient number of -0.643, which means that the correlation between compliance variables with noise due to noise is 0.643. Based on the criteria above, the relationship between the two variables is significant because the number of significance is P-value / Sig $0.005<0.05$. So, there is a relation between years of work with Noise Induce Hearing Loss, education and Noise Induce Hearing Loss, and compliance with the use of ear protectors with NIHL.
\end{abstract}

\section{ARTICLE HISTORY}

Received: April 20, 2021 Revised: June 25, 2021

Accepted: June 25, 2021

Published: June 30, 2021

(Online)

doi:

10.20473/jcmphr.v2i1.26439

\section{KEYWORDS}

NIHL; compliance of ear protector; hearing threshold value; education

\section{CORRESPONDING}

AUTHOR

Nyilo Purnami

$\bowtie$ nyilo@fk.unair.ac.id

Department of Ear Nose

Throat (ENT) - Head Neck

Surgery, Faculty of

Medicine, Universitas

Airlangga - Dr. Soetomo

General Hospital Surabaya, Jl. Mayjend Prof. Dr.

Moestopo 4-6, Surabaya, Indonesia

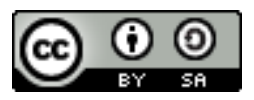

\section{INTRODUCTION}

The main effect of noise for humans is damage to the auditory sense which can cause some hearing disorders ranging from temporary deafness and permanent deafness depending on the intensity, length of time and individual sensitivity to the noise. Very loud noise or above $85 \mathrm{~dB}$ can cause a serious setback in hearing health conditions that can cause temporary hearing loss and can eventually cause permanent hearing loss. The prevalence of Noise Induce Hearing Loss (NIHL) in a study in the United States of $24 \%$ of adults under the age of 70 years experienced hearing loss. ${ }^{1}$ Research in Semarang in 2008 on employees of the Ahmad Yani airport in Semarang, found 14\% of hearing loss. ${ }^{2}$ According to OSHA (Occupational Health and Safety Association), when engineering and administrative control cannot be carried out 
or cannot provide adequate protection, companies must provide PPE and ensure workers use it. PPE is a tool used to minimize exposure to occupational hazards. Examples of PPE such as gloves, eye and leg protectors, hearing aids, helmets, respirators and protectors. ${ }^{3}$ The 2007 CDC's data reported about $85 \%$ of hearing loss due to work in the manufacturing sector. For all industrial sectors, Noise Induced Hearing Loss (NIHL) accounts for $14 \%$ of all occupational diseases. In America, 22 million workers are exposed to noisy hazards that exceed the threshold value every day and 10 million workers experience hearing loss due to noise exposure. The World Health Organization (WHO) in 2007 stated that the prevalence of deafness reached $4.2 \%$ in Indonesia. The incidence of hearing loss due to noise in the steel company labor force is $43.6 \%$ with the intensity of the noise level ranging between 88.3-112.8 dBA1. The continuity and type of personal protective equipment used also influences the amount of hearing loss caused by noise in the workplace. The use of ear protectors that are in accordance with the standard along with the continuity of optimal use can reduce the risk of hearing loss due to noise in the workplace. ${ }^{4}$

The washing process in the laundry raises noise caused by washing machines so that it can reduce the frequency of hearing officers and can disturb the psychological officers in it so that it can lead to the intensity of productivity of the laundry officer itself. With a working period of 8 hours per day or 40 hours per week and the characteristics of different laundry officers, the intensity of noise received from washing machines causes different sources of noise. The officer can experience health problems due to exposure to noise and the quality of the physical environment in the laundry that is not in accordance with the established quality standards. The determinant factor is the level of deafness of the officers due to the habit of officers using Ear protector. The Ear Protector Device is already a Standard Operating Procedure that must be obeyed while in the work environment for approximately eight hours per day., ${ }^{4,6}$

Based on the data obtained above, it is important to analyze the compliance of the use of ear protectors while working. Adherence to use Ear protectors greatly affect the likelihood of a person experiencing a more severe hearing loss.

\section{MATERIALS AND METHODS}

This study used cross sectional methods where the research measured and observed at the same time between the independent variable and the dependent variable. The aim of this study was to find out the relationship of staff/employee compliance with Laundry Installation and Sterilization at Dr Soetomo General Hospital as free variable with hearing loss as a dependent variable.

All noise level data and employee hearing levels collected in the data collection sheet were arranged in the form of tables and processed statistically. Processing and analysis of data with the help of computers. This study has a significance level of 0.05 or five percent.

\section{Inferential analysis}

This study used total sampling so the results of the research have represented the results of the population at staff/employees of laundry installation and sterilization of a hospital in Surabaya. Data from this study will be 
analyzed using univariate tests, namely the analysis carried out aims to explain or describe the characteristics of each variable.

This form of univariate analysis depends on the type of data. $^{7}$ Data results will be analyzed descriptively in the form of frequency and percentage. ${ }^{8,9}$

Once correlation coefficient is a number from -1 to 1 , or any number in-between. If two data sets move in lock step in the same direction and by the same amount, they have a correlation coefficient of 1 . If they move by the exact same amount but in the opposite direction, the number would be -1 . If the two sets of data seem to have no relationship at all, they have a correlation of 0 . In the above example where the Federal Reserve lowered interest rates, and the unemployment rate also lowered somewhat. The two numbers had a positive correlation (correlation coefficient greater than 0). But because they did not move the same amount, the number would be less than 1 .

\section{RESULTS}

Based on the table 1 above, it is known that the majority of respondents or laundry officers in is a group of age between 51-60 years, that is as many as 9 people $(52.9 \%)$ and for the age group 21-30 years as many as 3 people $(17.6 \%)$.

Table 1. Frequency Distribution of Laundry Officers Based on Age Group

\begin{tabular}{ccc}
\hline Age (Year) & N & Precentage (\%) \\
\hline $21-30$ & 3 & 17.6 \\
$31-40$ & 3 & 17.6 \\
$41-50$ & 2 & 11.9 \\
$51-60$ & 9 & 52.9 \\
\hline Total & 17 & 100 \\
\hline
\end{tabular}

Source: Primary Data, November 2018
Table 2. Frequency Distribution of Laundry Officers based on education level

\begin{tabular}{lcc}
\hline Education Level & N & $\begin{array}{c}\text { Percentage } \\
(\%)\end{array}$ \\
\hline Elementary School & 0 & 0 \\
Junior High School & 2 & 11.8 \\
Senior High School & 12 & 70.6 \\
Bachelor & 3 & 17.6 \\
No Education & 0 & 0 \\
\hline Total & 17 & 100 \\
\hline Source: Primary Data, November 2018 &
\end{tabular}

Based on the table 2 above, it was found that most of the laundry officers has a high school or high school education level of 12 people $(70.6 \%)$ and there are 2 people $(11.8 \%)$ each with a junior high school education level.

Table 3. Frequency Distribution of Laundry Officers Based on Work Period

\begin{tabular}{ccc}
\hline $\begin{array}{c}\text { Work Period } \\
\text { (Year) }\end{array}$ & N & $\begin{array}{c}\text { Percentage } \\
\text { (\%) }\end{array}$ \\
\hline $2-10$ & 4 & 23.5 \\
$11-20$ & 1 & 5.9 \\
$21-30$ & 10 & 58.8 \\
$31-40$ & 2 & 11.8 \\
\hline Total & 17 & 100 \\
\hline
\end{tabular}

Source: November 2018 Primary Data

In the table 3 above, it can be seen that most of the laundry officers has a working period of between 21-30 years, namely 10 people $(58.8 \%)$ and the lowest working period is between 11-20 years of work, namely 1 person $(5.9 \%)$.

The number of Pearson correlation coefficient of age correlation with NIHL is 0.832 . It means that the correlation is large between age variables hearing loss due to noise amounting to 0.832 . The correlation between age and NIHL showed significant correlation with a value of 0.00 . Based on the criteria above, the relationship between the two variables is significant because the number of significance is $\mathrm{P}$-value/Sig 0.00 $<0.05$. 
The number of Pearson correlation coefficients of work period with NIHL is 0.85 , which means that the correlation between variables in the working period with noise due to noise is 0.85 . It means a significant correlation with a value of 0.00 . Based on the criteria above, the relationship between the two variables is significant because the number of significance is $\mathrm{P}$ value/Sig $0.00<0.05$.

Table 4. Correlation of Education with Hearing

Loss

\begin{tabular}{llcc}
\hline & & Education & NIHL \\
\hline \multirow{4}{*}{ Education } & Pearson Correlation & 1 & $-.568^{*}$ \\
& Sig. (2-tailed) & & .017 \\
& $\mathrm{~N}$ & 17 & 17 \\
\multirow{4}{*}{ NIHL } & Pearson Correlation & $-.568^{*}$ & 1 \\
& Sig. (2-tailed) & .017 & \\
& $\mathrm{~N}$ & 17 & 17 \\
\hline
\end{tabular}

*. Correlation is significant at the 0.05 level (2-tailed).

In the table 4 above shows the number op Pearson correlation coefficient -0.568 which means that the correlation is large between age variables with noise due to hearing loss of 0.568 . The sign of one star (*) means a significant because the significance number is P-value/Sig $0.017<0.05$.

Table 5. Correlation of Compliance with NIHL

\begin{tabular}{llcc}
\hline & & Complience & NIHL \\
\hline \multirow{4}{*}{ Complience } & Pearson & 1 & $-.643^{* *}$ \\
& Correlation & & \\
& Sig. (2-tailed) & & .005 \\
& $\mathrm{~N}$ & 17 & 17 \\
& Pearson & $-.643^{* *}$ & 1 \\
\multirow{5}{*}{ NIHL } & Correlation & & \\
& Sig. (2-tailed) & .005 & \\
& $\mathrm{~N}$ & 17 & 17 \\
\hline
\end{tabular}

In the table 5 above shows the number of Pearson correlation coefficient -0.643 which means that the correlation between compliance variables with NIHL is 0.643 . Two-star sign $(* *)$ means a significant correlation with a value of 0.005 . Based on the criteria above, the relationship between the two variables is significant because the number of significance is $\mathrm{P}$-value/Sig 0.005 $<0.05$.

\section{DISCUSSION}

Based on the results of cross tabulation between significant correlations with a value of 0.00. Based on the criteria above the relationship between the two variables most of those who experience hearing loss are the age group of 50-60 years because the more age a person faces, the function of the organs in the body will decline, including hearing function. In addition, the factors of lifestyle outside the work environment also affect the level of exposure to noise intensity received by each individual. The influence of personal hygiene on the frequency of ear cleaning can also affect the barrier system in the outer ear to receive noise intensity. With the longer a person is exposed to noise exposure, the higher the risk that can be felt because hearing loss is accumulative so the longer the work period has been carried out, the greater the level of disturbance that will be suffered with no preventive measures such as the use of appropriate personal protective equipment and inspection periodically.

Based on the results of cross tabulation on the results of the study, it was found that the laundry officer shows the number of Pearson correlation coefficient -0.643 which means that the correlation is large between age variables with noise due to hearing loss of 0.643 . Two-star sign $(* *)$ means a significant correlation with a value of 0.005 . Based on the criteria above, the relationship between the two variables is significant because the significance number is $\mathrm{P}$-value/Sig 0.005 $<0.05$. There needs to be a follow-up effort to 
the officers so that every work wants and wants to wear personal hearing disorders according to age groups, the data shows that the above shows the Pearson correlation coefficient value of 0.832 , which means a large protective equipment (PPE). In addition, there needs to be a work rotation system. The noise intensity received by the officer will not be exposed to high noise sources continuously.

\section{CONCLUSION}

According to the result above there is some conclusion. The first conclusion is there is relationship between years of work with Noise Induce Hearing Loss and the correlation between two variables are significant. The second conclusion is there is a relationship between education and Noise Induce Hearing Loss. And the last is there is a relationship between compliance with the use of ear protectors and Noise Induce Hearing Loss.

\section{REFERENCES}

1. Agarwal G, Nagpure PS, Gadge SV (2016). Noise induced hearing loss in steel factory workers. Int J Occup Saf Health, 4(2), 34-43

2. Fuente A, Hickson L (2011). Noiseinduced hearing loss in Asia. Int $\mathrm{J}$ Audiol, 50(Sup 1), S3-S10
3. Kotarbinska E, Kozlowski E (2009). Measurement of effective noise exposure of workers wearing ear-muffs. Int J Occup Saf Ergon, 15(2), 193-200

4. Feder K, Michaud D, McNamee J, et al (2017). Prevalence of Hazardous Occupational Noise Exposure, Hearing Loss, and Hearing Protection Usage Among a Representative Sample of Working Canadians. J Occup Environ Med, 59(1), 92-113

5. Mohammadi G (2014). Occupational Noise Pollution and Hearing protection in selected industries. Iran J Health Saf Environ, Corpus ID: 56567312

6. Rangkooy HA, Rashnuodi P, Salehy MMA, et al (2018). Evaluation of NoiseInduced Hearing Loss on the Workers of one of the Ahvaz Steel Companies. Jundishapur J Health Sci, 10(1), e14258

7. Wictor IC, Xavier AA (2018). Noise perception and hearing protector use in metallurgical industries. Int $\mathrm{J}$ Occup Environ Saf, 2(1), 18-28

8. Royster JD (2017). Preventing NoiseInduced Hearing Loss. N C Med J, 78(2), 113-117

9. Musiba Z (2015). The prevalence of noise-induced hearing loss among Tanzanian miners. Occup Med, 65(5), 386-390 